SCIENTIFIC REPORT

\title{
Intraocular pressure and systemic blood pressure: longitudinal perspective: the Beaver Dam Eye Study
}

\author{
B E K Klein, R Klein, M D Knudtson
}

Br J Ophthalmol 2005;89:284-287. doi: 10.1136/bjo.2004.048710

\begin{abstract}
Aim: To investigate the relation between change in systemic blood pressures and change in intraocular pressure.

Methods: This was a population based study of people 4386 years old living in Beaver Dam, Wisconsin. Measurements at baseline (1988-90) and 5 year follow up of systemic blood pressures, intraocular pressures, and history of use of blood pressure medications.

Results: Intraocular pressures were significantly correlated with systolic and diastolic blood pressures at both baseline and follow up. There were significant direct correlations between changes in systemic blood pressures and changes in intraocular pressure. There was a $0.21(95 \% \mathrm{Cl}: 0.16$ to $0.27) \mathrm{mm} \mathrm{Hg}$ increase in IOP for a $10 \mathrm{~mm} \mathrm{Hg}$ increase in systolic and $0.43(0.35$ to 0.52$) \mathrm{mm} \mathrm{Hg}$ increase in IOP for a $10 \mathrm{~mm} \mathrm{Hg}$ increase in diastolic blood pressure. Further adjustment for diabetes and medication use did not alter these associations. Decreased systolic or diastolic blood pressures of more than $10 \mathrm{~mm} \mathrm{Hg}$ over 5 years were significantly associated with decreased IOP.

Conclusions: Reduced systemic blood pressure is associated with reduced intraocular pressure. This finding should be evaluated in other studies, especially with respect to the possibility of resultant decreased risk of open angle glaucoma.
\end{abstract}

l: ntraocular pressure (IOP) has been found to be associated with systemic blood pressure levels in population based studies. ${ }^{1-10}$ The relation appears to be reasonably consistent across the range of values of IOP and both systolic and diastolic blood pressures. It has been postulated that treatment of hypertension may place the eye at relatively increased risk of visual field deficits because of an imbalance in the relation of blood pressure to IOP. ${ }^{11}$ This thought has been given credence, in part, because of the clinical dictum that sudden lowering of blood pressure is associated with loss of visual field in some people. ${ }^{12}$ Blood pressure increases with age in most populations, and medical intervention has been successful in lowering blood pressure and the subsequent risk of the systemic sequelae of high blood pressure. There are limited data as to whether the moderate changes in blood pressure that often accompany treatment for hypertension are associated with synchronous changes in IOP. We evaluated these questions in data from the Beaver Dam Eye Study.

\section{METHODS}

A population based study of people 43-86 years of age $(\mathrm{n}=4926)$ was conducted in Beaver Dam, Wisconsin in 1988-90. Details of the census used to identify and locate study subjects have been published previously. ${ }^{13}$ A follow up examination was performed 5 years after baseline $(\mathrm{n}=3684)$. Institutional review board approval at the University of Wisconsin Medical School was granted for each phase of the study. Informed consent was obtained from study participants. The tenets of the Declaration of Helsinki were adhered to. During the study evaluations, blood pressures were obtained according to a modification of the Hypertension Detection and Follow-up Program protocol ${ }^{14}$ which entails three measurements, the last two of which are averaged in analyses. IOPs were obtained with a Goldmann applanation tonometer. A drop of Fluress (Armour, Kankakee, IL, USA) was instilled in each eye. The tonometer was set to $10 \mathrm{~mm} \mathrm{Hg}$. The measurement was taken as the examiner viewed the mires through the prism. When the end point was reached, the examiner moved the slit lamp away from the eye and recorded the reading. The procedure was repeated for the fellow eye. A medical history was obtained including items about hypertension and other medical conditions and a history of all medications currently used at each examination.

Means, standard deviations (SD), Pearson correlation coefficients, Mantel-Haenszel procedures, and linear regression models were performed using version 8.1 of SAS. ${ }^{15}$ Because we have found that both age and sex are related to the variables, analyses were adjusted for these characteristics. In comparing participants to non-participants and in cross sectional analyses of IOP and blood pressure, the relation between IOP and age was not linear, so age was adjusted for in four categories (43-54 years, 55-64 years, 65-74 years, and 75 years and older). All other models were adjusted for age continuously. The distributions of IOP, systolic (SBP), and diastolic blood pressure (DBP) were analysed on untransformed scales in linear regression models. Nonlinearity of any relation was tested by taking the square of the independent variable and testing for significance of the squared term. In all instances, the relations, when they existed, were determined to be linear. Blood pressure medications were analysed by creating a four level categorical variable (never used, baseline only, follow up only, and both examinations). Finally, stratified analyses were conducted with the four blood pressure medication categories and also with changes in blood pressure $(\leqslant 10 \mathrm{~mm} \mathrm{Hg}$, within $10 \mathrm{~mm} \mathrm{Hg}, \geqslant 10 \mathrm{~mm} \mathrm{Hg}$ ). Data are presented for right eyes only.

\section{RESULTS}

Those who participated at the baseline and 5 year follow up examinations were younger, had lower blood pressures, and lower IOP compared to live non-participants (table 1). Those who had died by the 5 year follow up were older, more likely to be men, and had lower DBP than participants. For those participating in both examinations, their mean SBP, DBP, and IOP were 130.8 (SD 19.4) $\mathrm{mm} \mathrm{Hg,} 77.8$ (10.5) mm Hg,

Abbreviations: DBP, diastolic blood pressure; IOP, intraocular pressure; SBP, systolic blood pressure 
Table 1 Baseline characteristics of participants and non-participants at 5 year follow up

\begin{tabular}{|c|c|c|c|c|c|}
\hline \multirow[b]{3}{*}{ Baseline } & \multirow{3}{*}{$\begin{array}{l}\text { Participants } \\
\text { At } 5 \text { year follow up } \\
\text { Mean (SD) or \% }\end{array}$} & \multicolumn{4}{|c|}{$\begin{array}{l}\text { Non-participants } \\
\text { At } 5 \text { year follow up }\end{array}$} \\
\hline & & \multicolumn{2}{|l|}{ Refused } & \multicolumn{2}{|l|}{ Dead } \\
\hline & & Mean (SD) or \% & p Value* & Mean (SD) or \% & p Value* \\
\hline Number & 3684 & 685 & & 557 & \\
\hline Age (years) & $60.4(10.5)$ & $62.7(11.7)$ & $<0.001$ & $72.2(9.4)$ & $<0.001$ \\
\hline Sex, $\%$ men & 43 & 41 & 0.71 & 52 & $<0.001$ \\
\hline $\mathrm{SBP}(\mathrm{mm} \mathrm{Hg})$ & $130.8(19.4)$ & $136.0(21.9)$ & $<0.001$ & $136.6(23.9)$ & 0.57 \\
\hline $\mathrm{DBP}(\mathrm{mm} \mathrm{Hg})$ & $77.8(10.5)$ & $78.3(12.1)$ & 0.01 & $72.8(12.0)$ & $<0.001$ \\
\hline $\mathrm{IOP}+(\mathrm{mm} \mathrm{Hg})$ & $15.4(3.3)$ & $15.7(3.5)$ & 0.04 & $15.3(3.6)$ & 0.51 \\
\hline
\end{tabular}

SBP, systolic blood pressure; DBP, diastolic blood pressure.

* $\mathrm{p}$ Values (Mantel-Haenszel test for sex and linear regression for continuous measures) are adjusted for age and sex (where appropriate) and compare refused and dead with participants only.

†IOP, intraocular pressure.

and 15.4 (3.3) $\mathrm{mm} \mathrm{Hg}$ (right eyes) at baseline, respectively. The mean pressures at follow up were: SBP, 129.7 (19.6) mm Hg; DBP 76.0 (10.7) $\mathrm{mm} \mathrm{Hg}$; and IOP 15.4 (3.2) mm Hg (right eyes), respectively.

In cross sectional analyses at baseline and follow up, SBP was associated with IOP such that $10 \mathrm{~mm} \mathrm{Hg}$ greater SBP was associated with about $0.3 \mathrm{~mm} \mathrm{Hg}$ greater IOP. For DBP, $10 \mathrm{~mm} \mathrm{Hg}$ greater pressure was associated with about $0.6 \mathrm{~mm} \mathrm{Hg}$ greater IOP (table 2). Relations were similar for data from left eyes. The greater coefficients for change in IOP with respect to DBP than for SBP, reflect the larger standard deviation for SBP. Thus, the changes associated with a standard deviation change in SBP and DBP are nearly the same (data not shown).

Over the 5 year interval, increased IOP was associated with increased blood pressure such that an increase of $10 \mathrm{~mm} \mathrm{Hg}$ in SBP was associated with an increase of about $0.2 \mathrm{~mm} \mathrm{Hg}$ in IOP, and an increase of $10 \mathrm{~mm} \mathrm{Hg}$ in DBP was associated with about $0.4 \mathrm{~mm} \mathrm{Hg}$ increase in IOP (table 2). The relation between change in blood pressures and change in IOP was similar for those with and without hypertension at baseline. In addition, there were no differences in the changes while considering age, sex, and diabetes status (data not shown). Also, there was no difference in the relation of change in IOP to change in blood pressure across the entire range of blood pressures.

In stratified analyses, there was a mean increase of 0.07 (SD 3.14) $\mathrm{mm} \mathrm{Hg}$ in IOP over the 5 year interval for those whose SBP was within $10 \mathrm{~mm} \mathrm{Hg}$ of their baseline blood pressure compared to an increase of 0.44 (3.07) $\mathrm{mm} \mathrm{Hg}$ for those whose SBP increased by $10 \mathrm{~mm} \mathrm{Hg}$ and a decrease of 0.59 (3.28) $\mathrm{mm} \mathrm{Hg}$ in IOP for those whose SBP decreased by $10 \mathrm{~mm} \mathrm{Hg}$ or more (table 3). Values for change in IOP for similar changes in DBP were 0.06 (3.06), 0.85 (3.44), and -0.79 (3.28), respectively.

In unadjusted analyses, people who were taking blood pressure medications at follow up only had the greatest drop in both SBP and DBP compared to all other categories of medication use. Similarly, the drop in IOP was greatest in those taking blood pressure medication at the 5 year follow up only (table 4). However, in multivariable analyses of change in IOP, only baseline use (of antihypertensives) was associated with significant change in IOP and this was an increase. Use of such medications at follow up only was associated with decreased IOP, but this was no longer significant (table 5). There was no effect of taking such medications at both examinations on change in IOP (above that caused by change in blood pressures).

Table 2 Relations between intraocular pressure (IOP) and blood pressure

\begin{tabular}{|c|c|c|c|c|c|}
\hline Dependent variable & Blood pressure & No & $\begin{array}{l}\text { Difference in dependent } \\
\text { variable } / 10 \mathrm{~mm} \mathrm{Hg} \\
\text { increase in blood pressure }\end{array}$ & $(95 \% \mathrm{Cl})$ & p Value \\
\hline Baseline IOP & Systolic & 4881 & 0.32 & $(0.27$ to 0.37$)$ & $<0.001$ \\
\hline Follow up IOP & Systolic & 3587 & 0.34 & $(0.28$ to 0.39$)$ & $<0.001$ \\
\hline Change in IOP & Change in systolic & 3549 & 0.21 & $(0.16$ to 0.27$)$ & $<0.001$ \\
\hline Baseline IOP & Diastolic & 4881 & 0.55 & $(0.46$ to 0.64$)$ & $<0.001$ \\
\hline Follow up IOP & Diastolic & 3586 & 0.57 & $(0.47$ to 0.67$)$ & $<0.001$ \\
\hline Change in IOP & Change in diastolic & 3548 & 0.43 & $(0.35$ to 0.52$)$ & $<0.001$ \\
\hline
\end{tabular}

Table 3 Change in intraocular pressure (IOP) stratified by blood pressure (BP) increments

\begin{tabular}{|c|c|c|c|c|}
\hline \multirow[b]{3}{*}{ Changes in IOP* } & \multicolumn{2}{|c|}{ Systolic blood pressure } & \multicolumn{2}{|c|}{ Diastolic blood pressure } \\
\hline & \multirow[b]{2}{*}{ No } & \multirow{2}{*}{$\frac{\text { Mean (SD) }}{\text { Change in IOP }}$} & \multirow[b]{2}{*}{ No } & \multirow{2}{*}{$\frac{\text { Mean (SD) }}{\text { Change in IOP }}$} \\
\hline & & & & \\
\hline $\mathrm{BP}$ increase by $\geqslant 10 \mathrm{~mm} \mathrm{Hg}$ & 845 & $0.44(3.07)^{*}$ & 423 & $0.85(3.44)^{*}$ \\
\hline BP stayed within $10 \mathrm{~mm} \mathrm{Hg}$ & 1717 & $0.07(3.14)$ & 2385 & $0.06(3.06)$ \\
\hline BP decreased by $\geqslant 10 \mathrm{~mm} \mathrm{Hg}$ & 987 & $-0.59(3.28)^{*}$ & 740 & $-0.79(3.28)^{*}$ \\
\hline
\end{tabular}


Table 4 Means at both baseline and follow up of blood pressure (BP) and intraocular pressure (IOP)*

\begin{tabular}{|c|c|c|c|c|c|}
\hline & \multirow[b]{2}{*}{ BP Med category } & \multirow[b]{2}{*}{ No } & \multirow{2}{*}{$\frac{\text { Baseline }}{\text { Mean (SD)† }}$} & \multirow{2}{*}{$\frac{\text { Follow up }}{\text { Mean (SD) }}$} & \multirow{2}{*}{$\begin{array}{l}\text { Change follow up, } \\
\text { baseline } \\
\text { Mean (SD) }\end{array}$} \\
\hline & & & & & \\
\hline \multirow[t]{5}{*}{ SBP } & None & 1916 & $125.0(16.8)$ & $125.6(17.9)$ & $0.7(13.8)^{*}$ \\
\hline & Baseline only & 123 & $129.3(19.5)$ & $134.5(21.6)$ & $5.1(18.7)^{*}$ \\
\hline & Follow up only & 433 & $139.7(21.0)$ & $130.1(19.6)$ & $-9.6(19.9)^{*}$ \\
\hline & Both & 1117 & 137.5 (19.5) & $136.0(20.3)$ & $-1.5(19.6)^{*}$ \\
\hline & All categories & 3609 & $130.8(19.4)$ & $129.7(19.6)$ & $-1.1(17.2)^{*}$ \\
\hline \multirow[t]{5}{*}{ DBP } & None & 1916 & $76.4(9.5)$ & $75.9(10.0)$ & $-0.5(9.3)^{*}$ \\
\hline & Baseline only & 123 & $75.8(11.0)$ & 76.3 (11.9) & $0.5(11.5)$ \\
\hline & Follow up only & 433 & $82.0(12.2)$ & $75.4(12.0)$ & $-6.7(12.0)^{*}$ \\
\hline & Both & 1116 & $79.0(10.7)$ & $76.5(11.0)$ & $-2.5(10.6)^{*}$ \\
\hline & All categories & 3608 & $77.8(10.5)$ & $76.0(10.7)$ & $-1.8(10.4)^{*}$ \\
\hline \multirow[t]{5}{*}{ IOP } & None & 1897 & $15.0(3.1)$ & $15.2(3.1)$ & $0.2(3.0)^{*}$ \\
\hline & Baseline only & 120 & $15.5(3.4)$ & $16.3(4.2)$ & $0.8(4.4)^{*}$ \\
\hline & Follow up only & 418 & $15.9(3.4)$ & $15.4(3.5)$ & $-0.5(3.3)^{*}$ \\
\hline & Both & 1101 & $15.7(3.5)$ & $15.6(3.3)$ & $-0.2(3.3)^{*}$ \\
\hline & All categories & 3556 & $15.4(3.3)$ & $15.3(3.2)$ & $0.0(3.2)$ \\
\hline
\end{tabular}

The results between the relation of IOP to BP were not altered after eliminating those on ocular hypotensive agents. Ocular surgery (nearly all because of cataract extraction) in the interval between examinations did not alter these findings.

There were 1305 participants at baseline and 1600 at follow up who were taking antihypertensive agents. Of these, 746 at baseline and 903 at follow up were taking only one agent. In addition, even participants taking only one agent often had had a change in that medication between baseline and follow up. In an attempt to determine whether a class of antihypertensive agents had any relative advantage with respect to IOP, we computed changes in IOP as a function of age, sex, IOP at baseline, use of $\beta$ blockers, use of diuretics, use of other antihypertensive agents, and change in SBP or DBP. We limited our analyses to three categories of antihypertensive agents because numbers in other categories were low. We found greater change in IOP in those taking $\beta$ blocking agents especially at follow up only (data not shown). However, it may be that using a combination of agents including $\beta$ blockers may, in part, account for this finding.

\section{DISCUSSION}

We have found that change in IOP is directly and significantly associated with changes in systemic blood pressures. This would suggest that treatment of blood pressure might have an effect on risk of developing glaucoma, as IOP is probably the most important risk factor for glaucoma in general populations. We have previously shown that those with higher IOP at baseline were more likely to have larger cup:disc ratio 5 years later. ${ }^{16}$ While our findings do not directly indicate a beneficial effect of reduced blood pressure on the risk of glaucoma, they are compatible with that possibility.

Our data do not define the mechanism linking the observations we found. However, Bill ${ }^{17}$ demonstrated that variations in SBP resulted in (small) changes in aqueous

Table 5 Multivariable model for change in intraocular pressure (IOP)* and change in systolic and diastolic blood pressure (BP)

\begin{tabular}{|c|c|c|c|}
\hline Parameter & $\beta$ coefficient & $95 \% \mathrm{Cl}$ & p Value \\
\hline \multicolumn{4}{|l|}{ (A) Systolic blood pressure } \\
\hline Age/ 10 (years) & 0.03 & -0.01 to 0.12 & 0.49 \\
\hline Female sex & 0.03 & -0.15 to 0.22 & 0.73 \\
\hline Baseline IOP & -0.48 & -0.50 to -0.45 & $<0.001$ \\
\hline High BP medications & NA & NA & $0.03^{*}$ \\
\hline Neither examination & 0.02 & -0.20 to 0.24 & 0.86 \\
\hline Baseline only & 0.76 & 0.24 to 1.28 & 0.004 \\
\hline Follow up only & $\begin{array}{l}-0.07 \\
\text { Referencet }\end{array}$ & -0.38 to 0.25 & 0.68 \\
\hline Diabetes & 0.17 & -0.00 to 0.34 & 0.05 \\
\hline $\begin{array}{l}\text { Increase in systolic BP/10 (mm Hg) } \\
\text { (B) Diastolic blood pressure }\end{array}$ & 0.20 & 0.15 to 0.26 & $<0.001$ \\
\hline Age/10 (years) & 0.03 & -0.01 to 0.12 & 0.49 \\
\hline Female sex & 0.02 & -0.16 to 0.21 & 0.79 \\
\hline Baseline IOP† & -0.47 & -0.50 to -0.44 & $<0.001$ \\
\hline High BP medications & NA & NA & $0.03^{*}$ \\
\hline Neither examination & -0.02 & -0.24 to 0.19 & 0.83 \\
\hline Baseline only & 0.75 & 0.24 to 1.27 & 0.004 \\
\hline Follow up only & -0.05 & -0.36 to 0.26 & 0.75 \\
\hline Diabetes & 0.19 & 0.01 to 0.36 & 0.03 \\
\hline Increase in diastolic BP/10 (mm Hg) & 0.43 & 0.34 to 0.52 & $<0.001$ \\
\hline
\end{tabular}


humour formation, possibly related to increased capillary pressure in the ciliary body. This could result in increased IOP. Blood pressure may affect episcleral venous pressure, which is important in regulating the flow of aqueous across the trabecular meshwork into Schlemm's canal. ${ }^{18}{ }^{19}$ It is also possible that decreased blood pressure may alter outflow facility through some unidentified means. However, the association of decreased IOP to decreased blood pressure may be related to the effect of specific antihypertensive agents that directly affect the formation or egress of aqueous in the eye. Such agents that might have such effects include ethacrynic acid, ${ }^{20}{ }^{21}$ other diuretic agents, calcium channel blockers, ${ }^{22}$ selective $\alpha$ agonists, ${ }^{23}$ and $\beta$ blockers. ${ }^{24-26}$

Leske et $a l^{11}$ found an association between systemic and ocular hypertension and between high DBP and open angle glaucoma. They found that treatment for systemic hypertension was not associated with increased risk of open angle glaucoma, but made no mention of a possible protective effect. They did find an association between low perfusion pressure and open angle glaucoma. In summing up, they concluded that they could not find an independent effect of blood pressure on open angle glaucoma. While we cannot directly test for an association between change in blood pressure and risk of glaucoma, our data are compatible with the possibility that lowered blood pressure is associated with lower IOP. This may well have a positive benefit in the future for reduction in risk of open angle glaucoma.

In multivariable analyses, we found that those who took antihypertensive agents at baseline only had increased blood pressures as well as increased IOPs at follow up. This could represent a rebound effect. We also found that diabetes at the baseline examination was significantly and positively associated with change (increase) in IOP. Diabetes has been found to be associated with increased IOP in other studies, ${ }^{27-29}$ although the reasons are not known.

A limitation of our study is that all those evaluated at the baseline examination did not participate in the follow up 5 years later, and the majority of non-participants had died. Since cardiovascular disease is the leading cause of death, it is possible that this has had an effect on our estimates of a relation between change in blood pressure and change in IOP. Since we are likely to have lost those with highest blood pressures, in the range we could test, we found no differences in the relation between change in IOP and change in blood pressures. In addition, our cross sectional estimates of the relations between blood pressures and IOP were similar for the baseline and for the 5 year examination, suggesting that there may not have been much effect of the loss as a result of mortality. We note that only one IOP measurement was taken in each eye at each visit. Measurement error would influence our estimate of relations. We expect that such variability would be random and might bias our results to the null.

\section{Authors' affiliations}

B E K Klein, R Klein, M D Knudtson, Department of Ophthalmology and Visual Sciences, University of Wisconsin Medical School, Madison, WI, USA

This study was supported by National Institutes of Health grant EYO6594 (Klein R, Klein BEK).

Proprietary or financial interests: None.
Correspondence to: Barbara E K Klein, MD, MPH, Department of Ophthalmology and Visual Sciences, University of Wisconsin-Madison, 610 North Walnut Street, 4th Floor WARF, Madison, WI 53726-2336, USA; kleinb@epi.ophth.wisc.edu

Accepted for publication 1 August 2004

\section{REFERENCES}

1 Bengtsson B. Some factors affecting the distribution of intraocular pressures in a population. Acta Ophthalmol (Copenh) 1972;50:33-46

2 Bulpitt CJ, Hodes C, Everitt MG. Intraocular pressure and systemic blood pressure in the elderly. Br J Ophthalmol 1975;59:717-20.

3 Kahn HA, Leibowitz HM, Ganley JP, et al. The Framingham Eye Study. II. Association of ophthalmic pathology with single variables previously measured in the Framingham Heart Study. Am J Epidemiol 1977;106:33-41.

4 Klein BE, Klein R. Intraocular pressure and cardiovascular risk variables. Arch Ophthalmol 1981;99:837-9.

5 Klein BE, Klein R, Linton KL. Intraocular pressure in an American community. The Beaver Dam Eye Study. Invest Ophthalmol Vis Sci 1992;33:2224-8.

6 Wu SY, Leske MC. Associations with intraocular pressure in the Barbados Eye Study. Arch Ophthalmol 1997;115:1572-6.

7 Tielsch JM, Katz J, Sommer A, et al. Hypertension, perfusion pressure, and primary open-angle glaucoma. A population-based assessment. Arch Ophthalmol 1995;113:216-21.

8 Dielemans I, Vingerling JR, Algra D, et al. Primary open-angle glaucoma, intraocular pressure, and systemic blood pressure in the general elderly population. The Rotterdam Study. Ophthalmology 1995;102:54-60.

9 Healey PR, Mitchell P, Smith W, et al. The influence of age and intraocular pressure on the optic cup in a normal population. J Glaucoma 1997;6:274-8.

10 Foster PJ, Machin D, Wong TY, et al. Determinants of intraocular pressure and its association with glaucomatous optic neuropathy in Chinese Singaporeans: the Tanjong Pagar Study. Invest Ophthalmol Vis Sci 2003;44:3885-91.

11 Leske MC, Warheit-Roberts L, Wu SY. Open-angle glaucoma and ocular hypertension: the Long Island Glaucoma Case-control Study. Ophthalmic Epidemiol 1996;3:85-96.

12 Piltz-Seymour JR, Stone RA. Glaucoma associated with systemic disease. In: Ritch R, Shields MB, Krupin T, eds. The glaucomas. 2nd ed. St Louis: Mosby, 1996:1 157-76.

13 Campbell JA, Palit CD. Total digit dialing for a small area census by phone. Proceedings of the American Statistical Society 1988:1249-51.

14 Hypertension Detection and Follow-up Program Cooperative Group. The hypertension detection and follow-up program. Prev Med 1976;5:207-215

15 SAT Institute Inc. SAT/SAS user's guide, version 8. Cary, NC: SAS Institute, 1999.

16 Klein BE, Klein R, Jensen SC. Changes in the optic disc over a five-year interval. The Beaver Dam Eye Study. Curr Eye Res 1997;16:738-40.

17 Bill A. The role of ciliary body blood flow and ultrafiltration in aqueous humor formation. Exp Eye Res 1973;16:287-98.

18 Bill A. Blood circulation and fluid dynamics in the eye. Physiol Rey 1975:55:383-417.

19 Moses RA. Intraocular pressure. In: Moses RA, ed. Adler's physiology of the eye:clinical application. 7th ed. St Lovis: Mosby, 1981.

20 Epstein DL, Freddo TF, Bassett-Chu S, et al. Influence of ethacrynic acid on outflow facility in the monkey and calf eye. Invest Ophthalmol Vis Sci 1987;28:2067-75

21 Melamed S, Kotas-Neumann R, Barak A, et al. The effect of intracamerally injected ethacrynic acid on intraocular pressure in patients with glaucoma. Am J Ophthalmol 1992;113:508-12.

22 Abelson MB, Gilbert CM, Smith LM. Sustained reductions of intraocular pressure in humans with the calcium channel blocker verapamil. Am J Ophthalmol 1988; 105:155-9.

23 Harrison R, Kaufmann CS. Clonidine. Effects of a topically administered solution on intraocular pressure and blood pressure in open-angle glaucoma. Arch Ophthalmol 1977;95:1368-73.

24 Bromberg BB, Gregory DS, Sears ML. Beta-adrenergic receptors in ciliary processes of the rabbit. Invest Ophthalmol Vis Sci 1980;19:203-7.

25 Brubaker RF, Nagataki S, Bourne WM. Effect of chronically administered timolol on aqueous humor flow in patients with glaucoma. Ophthalmology 1982;89:280-3.

26 Dailey RA, Brubaker RF, Bourne WM. The effects of timolol maleate and acetazolamide on the rate of aqueous formation in normal human subjects. Am J Ophthalmol 1982;93:232-7.

27 Klein BE, Klein K, Moss SE. Intraocular pressure in diabetic persons. Ophthalmology 1984;91:1356-60.

28 Traisman HS, Alfano JE, Andrews J, et al. Intraocular pressure in juvenile diabetics. Am J Ophthalmol 1967;64:1 149-51.

29 Carel RS, Korczyn AD, Rock $M$, et al. Association between ocular pressure and certain health parameters. Ophthalmology 1984;91:311-14. 